\title{
Research on Empirical Formula of Displacement Efficiency in Bohai Oilfield
}

\author{
Yu Duan, Shaopeng Wang, Meinan Wang, Jinyi Li, Gang Wang \\ Bohai Oilfield Research Institute of CNOOC CHINA Ltd., Tianjin, China \\ Email: duanyu2@cnooc.com.cn
}

How to cite this paper: Duan, Y., Wang, S.P., Wang, M.N., Li, J.Y. and Wang, G. (2018) Research on Empirical Formula of Displacement Efficiency in Bohai Oilfield. Journal of Power and Energy Engineering, 6, 27-31.

https://doi.org/10.4236/jpee.2018.69004

Received: August 16, 2018

Accepted: September 8, 2018

Published: September 11, 2018

Copyright $\odot 2018$ by authors and Scientific Research Publishing Inc. This work is licensed under the Creative Commons Attribution International License (CC BY 4.0).

http://creativecommons.org/licenses/by/4.0/

\begin{abstract}
Displacement efficiency is an important index of water drive oilfield. This article takes water drive oilfield as the object to analyze the influence factors of displacement efficiency in limit water cut stage of water drive oilfield. The displacement efficiency experimental data of 99 cores which come from 65 development wells of 34 oilfields have been collected. The authors use the method of multiple linear regression analysis to establish a new empirical formula of displacement efficiency. The relative error of the empirical formula is less than $7 \%$ compared to the experimental data.
\end{abstract}

\section{Keywords}

Bohai Oilfield, Water Drive, Displacement Efficiency, Empirical Formula

\section{Introduction}

The displacement efficiency is the ratio that is the volume of the produced oil to the volume of oil in place [1] [2]. The displacement efficiency at limited water cut is an important evaluation index which can calculate recovery efficiency of reserve and evaluate the development efficiency of water-drive field. At present, displacement efficiency at limited water cut can be obtained by water flooding experiment of core and experience formula. But the development cost of offshore oilfield is high. The core data are relatively few.

In addition, due to the influence of sample data representation, the existing empirical formula has a poor adaptability to Bohai oilfield. At present, the widely used empirical formula of displacement efficiency was established by $\mathrm{Mr}$. Yu Qitai (Equation (1)). This empirical formula was established based on the experimental data of water flooding experiment of onshore oilfields in the US, the Soviet Union and China, thus the empirical formula has poor adaptability to offshore oil fields. The relative error of the empirical formula already exceeds 
$10 \%$ compared to the experimental data of cores in Bohai oilfield. So, the displacement efficiency of Bohai oilfield is difficult to obtain. It is necessary to establish an empirical formula of displacement efficiency based on the experimental data of water flooding experiment of Bohai oilfield.

$$
E_{D}=0.5757-0.1157 \lg \mu_{o}+0.03753 \lg k,
$$

where $E_{D}$ is displacement efficiency, $f, \mu_{o}$ is oil viscosity in place, mPa.s; $k$ is permeability, $\mathrm{mD}$.

This article takes displacement efficiency at limited water cut of Bohai oilfield as object, by collecting data of developed oil field, and the influence factors of displacement efficiency are researched, using the method of multiple linear regression analysis to establish a new empirical formula of displacement efficiency. The relative error of the empirical formula is less than $7 \%$ compared to the experimental data. The empirical formula enriches the method of displacement efficiency calibration in Bohai Oilfield.

\section{Method}

\subsection{The Analyze of Influence Factors of Displacement Efficiency in Limited Water Cut Stage}

There are many influence factors of displacement efficiency. In this paper, by literature research [3]-[8] and reservoir method, the influence factors are permeability, porosity, oil viscosity and the pore volume multiple of injected water.

Reservoir permeability and porosity characterize the influence of rock microscopic pore structure on percolation capacity. The large number of experimental results shows that there is a positive correlation between displacement efficiency and reservoir permeability and porosity. If the reservoir porosity and permeability is higher, displacement efficiency is higher.

The oil viscosity in place has great influence on oil displacement efficiency. If the oil viscosity in place is low, then the pistons drive is formed easily during water displacement.

The pore volume ratio of injected water is defined as the ratio of the volume of injected water to reservoir pore volume. Experiments show that with the increase of injection multiple, displacement efficiency increases. But the increase rate is different at different stages of development and different pore volume multiple of injected water. Especially, the increase rate is smaller when the development of oil reservoir is at high water cut period. Because this article takes displacement efficiency at limited water cut of Bohai oilfield as object, the pore volume multiple of injected water is very high, the pore volume multiple of injected water has little influence on oil displacement efficiency.

\subsection{Collection and Selection of Data}

In this paper, the displacement efficiency experimental data of 118 rocks which come from 65 development wells of 34 oilfields have been collected. On this basis, the data which has unreasonable experimental condition and inaccurate re- 
sult is rejected. Finally, the displacement efficiency experimental data of 99 cores which come from 65 development wells of 34 oilfields has been collected as sample data. The sample data covers the typical oil fields in Bohai oilfield, which is highly representative.

In order to further verify the data reliability, the correlation between three influence factors and displacement efficiency is analyzed. Figure 1 shows that permeability, porosity and oil viscosity in place of sample data has good relation with displacement efficiency. The sample data are reliable.

\subsection{Empirical Formula Establishment}

The process of empirical formula establishment the formula is the process of obtaining the relationship between three influence factors and displacement efficiency. There are two methods in regression formula, one method is multivariate linear regression (Equation (2)); the other method is multivariate nonlinear regression (Equation (3)).

$$
\begin{gathered}
\hat{y}=a_{1} x_{1}+a_{2} x_{2}+\cdots+a_{n} x_{n}+b, \\
\hat{y}=f\left(x_{1}\right)+f\left(x_{2}\right)+\cdots+f\left(x_{n}\right)+b,
\end{gathered}
$$

The method of multivariate nonlinear regression has high accuracy, but the calculation is complicated and difficult to operate. In the conditions of guaranteeing the accuracy, the method of multivariate linear regression is easy to operate and simple to calculate. By comparison, the method of multivariate linear regression is used to establish empirical formula. Considering that the range of permeability and oil viscosity in place is very large, the two parameters are expressed in logarithmic form. The sample data is substituted into the Equation (2), there are 99 equations (Equation (4)):

$$
\left\{\begin{array}{c}
E_{D 1}=a_{1} \phi_{1}+a_{2} \log k_{1}-a_{3} \log \mu_{1}+b \\
E_{D 2}=a_{1} \phi_{1}+a_{2} \log k_{1}-a_{3} \log \mu_{1}+b \\
\quad \vdots \\
E_{D 99}=a_{1} \phi_{99}+a_{2} \log k_{99}-a_{3} \log \mu_{99}+b
\end{array},\right.
$$

Use least square method and Gaussian elimination method to solve equations.

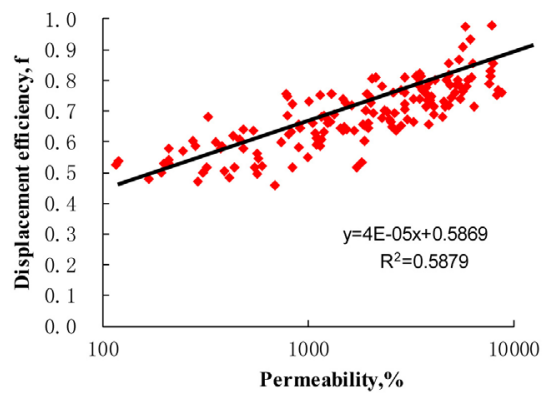

(a)

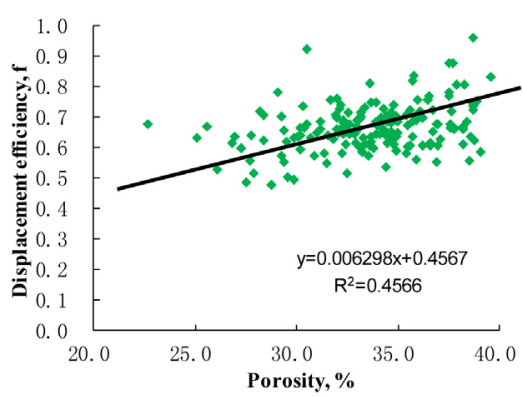

(b)

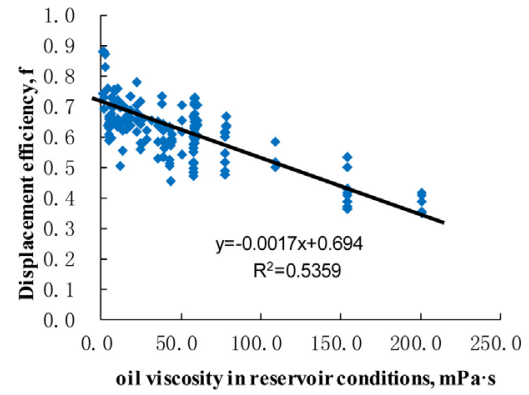

(c)

Figure 1. Comparison displacement efficiency between permeability, porosity and oil viscosity in place. (a) Comparison displacement efficiency between permeability; (b) Comparison displacement efficiency between porosity; (c) Comparison displacement efficiency between oil viscosity in place. 
The solution process is as follows: Use Gaussian elimination method to solve Equation (4). The values of $a_{1}, a_{2}, \cdots, a_{6}$ and $b$ are obtained.

Through a series of operations, finally, a new empirical formula (Equation (5)) of displacement efficiency is established.

$$
E_{D}=0.002 \phi+0.053 \lg k-0.034 \lg \mu_{o}+0.443,
$$

where $E_{D}$ is displacement efficiency, $f ; \phi$ is porosity, $\%$; $k$ is permeability, $\mathrm{mD} ; \mu_{o}$ is oil viscosity in place, $\mathrm{mPa} \cdot \mathrm{s}$.

\section{Results and Discussion}

New empirical formula is used to calculate displacement efficiency of sample rocks. The calculation results are shown in the figure (Figure 2). Figure 2 shows that the calculated values are close to the experiment value. The relative error of the empirical formula is less than $7 \%$ compared to the experimental data.

The general empirical formula is based on a specific set of data, so it has a specific scope of application. By combing the sample data, the scope of parameters of empirical formula is confirmed (Table 1 ). Table 1 shows that the formula is applicable to heavy oil reservoir with good properties.

\section{Conclusions}

1) Confirm the influence factors of displacement efficiency at limited water cut. The influence factors are permeability, porosity and oil viscosity in place.

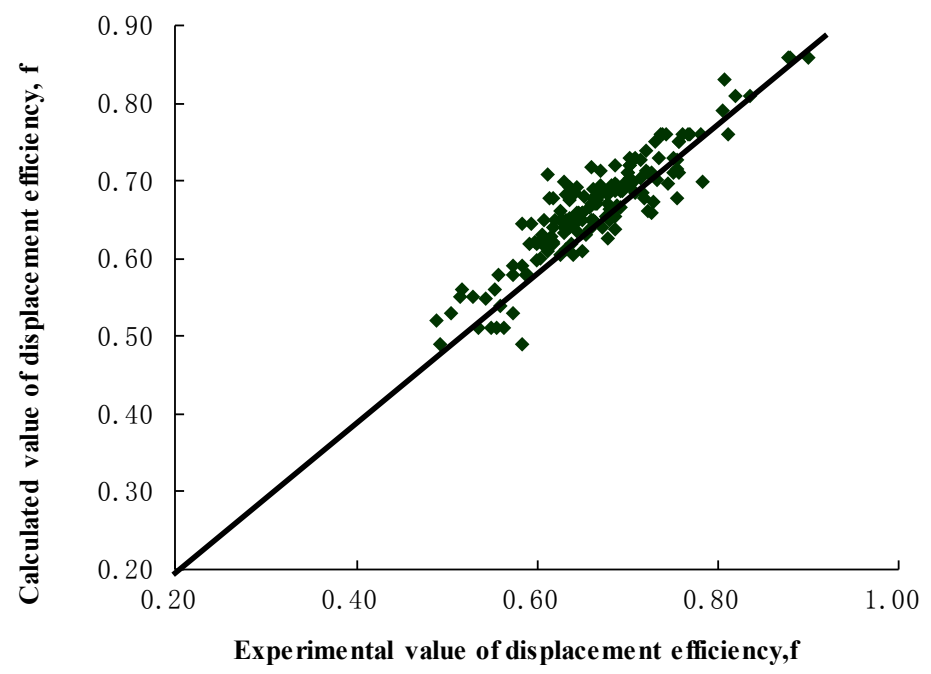

Figure 2. Comparison diagram between calculated value of displacement efficiency and experimental value of displacement efficiency.

Table 1. The scope of application of empirical formula.

\begin{tabular}{cccc}
\hline Parameter & Porosity \% & Air Permeability $\mathrm{mD}$ & $\begin{array}{c}\text { Oil viscosity in place } \\
\mathrm{mPa} \cdot \mathrm{s}\end{array}$ \\
\hline Range & $10.3-40.1$ & $42.0-9720.0$ & $8.2-252.7$ \\
Mean & 30.6 & 2367.0 & 52.9 \\
\hline
\end{tabular}


2) Establish a new empirical formula of displacement efficiency. The relative error of the empirical formula is less than $7 \%$ compared to the experimental data.

\section{Conflicts of Interest}

The authors declare no conflicts of interest regarding the publication of this paper.

\section{References}

[1] Zhang, T.X. and Li, L.B. (2004) Determination of Displacement Efficiency and Volumetric Sweep Efficiency. Xinjiang Petroleum Geology, 25, 202-203.

[2] Yan, Z. (2010) Discussion on Prediction of Waterflooding Displacement Efficiency with Field Production Data. Petroleum Geology and Recovery Efficiency, 17, 99-101.

[3] Lu, P. (1985) Experimental Study on the Factors Affecting Sweep Efficiency. Petroleum Exploration and Development, 12, 54-60.

[4] Lan, Y.B., Zhao, Y.S. and Wei, G.Z. (2005) Analysis of Displacement Efficiency of Field Pressure Coring and Lab Test. Journal of Daqing Petroleum Institute, 29, 43-45.

[5] Li, J.F. and Qu, Z.H. (2002) A Study on the Change of Efficiency in Waterflood Reservoirs by Using Multimodal Experiment. Journal of Northwest University (Natural Science Edition), 26, 47-54.

[6] Xu, Y.P., Mu, W.Z. and Song, G.G. (2005) Experiment of Water Injection Rate Limit in Waterflooding Development in Lamadian Oilfield. Journal of Daqing Petroleum Institute, 29, 26-30.

[7] Luo, H. and Yu, Q.T. (2000) Study of Oil Displacement Efficiency for Fluvial and Delta Facies Reservoirs of Oilfield in China. Fault-Block Oil \& Gas Field, 7, 46-47.

[8] Wang, R.Y. (2008) A Calculating Method for Waterflooding Sweep Efficiency of Core Based on Maximal Entropy. Fault-Block Oil \& Gas Field, 15, 91-93. 